\section{Innovation in compression: smart bandage technology to improve bandage application and monitoring}

\section{Jerry Hutchinson}

Hutchinson WoundTech Limited, UK

\section{Introduction}

Although high compression delivered by elastic bandages or hosiery is widely accepted as the standard first line care for patients with venous disease but without significant arterial impairment ${ }^{1-6}$ the application of bandages in particular is subject to significant variation. In most cases the interface pressure, effectively the compression dose, is not accurately known and is likely to be different from the ideal graduated compression intended on application. ${ }^{7,8}$ Furthermore, as the dimensions of the affected limb change under the influence of external compression, the interface pressure changes (REF). ${ }^{1}$ Variability in the application and sustainability of interface pressure is likely to lead to variable clinical efficacy, for example, healing rates. Indeed, the healing rates reported for VLU vary considerably. ${ }^{9-19}$

Technical solutions to variability in application of bandages include printed ovals or rectangles that change to circles or squares at the correct bandage extension; markings on orthostatic devices that are matched to a scale; bandage application at full stretch. Direct measurement of interface

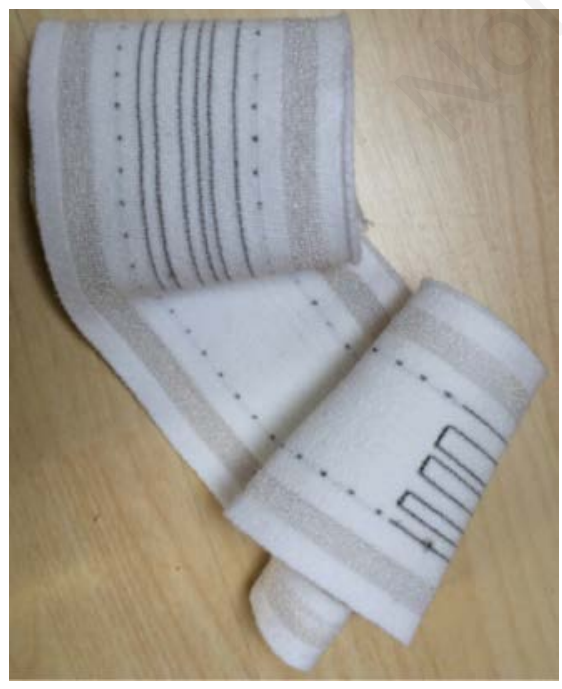

Figure 1. Functional prototype Smart Bandage showing three transducers knitted into a compression bandage. pressure may be used on application and for monitoring ${ }^{20}$ but pressure is usually measured at only one anatomic location. Despite these solutions bandage application remains variable, and the application of reduced compression by reduced stretch in the presence of arterial impairment is largely semiquantitative at best.

\section{A new technology to report inter- face pressure}

Laplace's Law governs the calculation of interface pressure applied by a material on a surface with a circular cross section. The accuracy of Laplace's algorithm is known. ${ }^{21}$ The extension of an elastic material can be measured accurately using strain gauge technology and the tension throughout its range of extension can be measured. The tension value is used with the radius of the surface to derive the interface pressure. This principle has been used to develop a functional prototype smart bandage (SB).

The components of SB are an elastic bandage with the desired stretch properties into which three silver strain gauge transducers are knitted (Figure 1); a connection point at a bandage extremity; digital electronics to detect the transducer output and wirelessly connect to a user interface; a Bluetooth user interface, for example a Smartphone or tablet, with an app that reports the consistency and values of applied pressure in real time. Pressure is calculated using Laplace's Law. The tension in the bandage material is derived from its known properties which are pre-programmed into the electronics. Upon application the bandage extension, from which tension is computed, is reported by the transducer. Limb dimensions are derived by direct measurement of the patient's leg and manually entered via the user interface. As the bandage is applied the system uses its integrated algorithm to show a real-time visual display of the accuracy of application, reporting the interface pressure as an absolute value. A colour-based scale shows yellow when pressure is too low, green when it is as intended, and red when over the target value. The bandager can thereby adjust the extension to achieve target pressure in real time.

At the time of writing, a functional prototype is developed and is subject to a development agreement with a commercial partner. The anticipated benefits of SB include higher quality of bandage application; real-time monitoring of compression in-use; improved healing through greater accuracy in bandage application and main-
Correspondence: Jerry Hutchinson, Hutchinson WoundTech Limited, UK.

E-mail: jhutchinson31@gmail.com

This work is licensed under a Creative Commons Attribution 4.0 License (by-nc 4.0).

CC Copyright J. Hutchinson, 2017

Licensee PAGEPress, Italy

Veins and Lymphatics 2017; 6:6631

doi:10.4081/vl.2017.6631

tenance of dose; ability to account accurately for lower compression in patients with significant arterial impairment; washability in re-usable products.

\section{References}

1. Moneta GL, Partsch H. Compression for venous ulceration. In: Gloviczki P, ed. Handbook of venous disorders. 3rd ed. London: Hodder Arnold; 2009. pp 348-358.

2. Mosti G, Mattaliano V, Polignano R, Masina M. Compression therapy in the treatment of leg ulcers. Acta Vulnol 2009; 7:1-20.

3. Comerota AJ. Intermittent pneumatic compression: physiologic and clinical basis to improve management of venous leg ulcers. J Vasc Surg 2011;53:1121-9.

4. Kahle B, Hermanns HJ, Gallenkemper G. Evidence-based treatment of chronic leg ulcers. Dtsch Arztebl Int 2011;108:231-7.

5. O’Meara S, Cullum N, Nelson EA, Dumville JC. Compression for venous leg ulcers. Cochrane Database Syst Rev 2012;11:CD000265.

6. Neumann HA, Cornu-Thénard A, Jünger M, et al. Evidence-based (S3) guidelines for diagnostics and treatment of venous leg ulcers. J Eur Acad Dermatol Venereol 2016 [Epub ahead of print].

7. Lee AJ, Dale JJ, Ruckley CV, et al. Compression therapy: effects of posture and application techniques on initial pressures delivered by bandages of different physical properties. Eur J Vasc Endovasc Surg 2006;31:542-52.

8. Dale JJ, Ruckley CV, Gibson B, et al. Multi-layer compression: comparison of four different four-layer bandage systems applied to the leg. Eur J Vasc Endovasc Surg 2004;27:94-9.

9. Ukat A, Konig M, Vanscheidt W, Münter KC. Short-stretch versus multilayer compression for venous leg ulcers: a comparison of healing rates. J Wound Care 2003;12:139-43. 
10. Watson JM, Kang'ombe AR, Soares MO, et al. VenUS III: a randomised controlled trial of therapeutic ultrasound in the management of venous leg ulcers. Health Technol Assess 2011;15:1-192.

11. Weller CD, Evans SM, Staples MP, et al. Randomized clinical trial of threelayer tubular bandaging system for venous leg ulcers. Wound Repair Regen 2012;20:822-9.

12. Harding $\mathrm{KG}$, Aldons $\mathrm{P}$, Edwards $\mathrm{H}$, et al. Effectiveness of an acellular synthetic matrix in the treatment of heard-toheal leg ulcers. Int Wound $J$ 2013;11:129-37.

13. Margolis DJ, Allen-Taylor L, Hoffstad $\mathrm{O}$, Berlin JA. Healing diabetic neuropathic foot ulcers: are we getting better? Diabet Med 2005;22:172-6.
14. Franks PJ, Moffatt CJ. Health related quality of life in patients with venous ulceration: use of the Nottingham health profile. Qual Life Res 2001;10:693700.

15. Thomas DR, Diebold MR, Eggemeyer LM. A controlled, randomized, comparative study of a radiant heat bandage on the healing of stage 3-4 pressure ulcers: a pilot study. J Am Med Dir Assoc 2005;6:46-9.

16. Benigni JP, Lazareth I, Parpex P, et al. Efficacy, safety and acceptability of a new two-layer bandage system for venous leg ulcers. J Wound Care 2007;16:385-90.

17. van Lijswijk L. Multi-Centre Leg Ulcer Study Group. Full-thickness leg ulcers: patient demographics and predictors of healing. J Fam Pract 1993;36:625-32.
18. Lyon RT, Veith FJ, Bolton L, Machado F. Venous Ulcer Study Collaborators. Clinical benchmark for healing of chronic venous ulcers. Am J Surg 1998;176:172-5.

19. Milic DJ, Zivic SS, Bogdanovic DC, et al. Risk factors related to the failure of venous leg ulcers to heal with compression treatment. J Vasc Surg 2009;49: 1242-7.

20. Partsch H, Mosti G. Comparison of three portable instruments to measure compression pressure. Int Angiol 2010;29:426-30.

21. Thomas S. The production and measurement of sub-bandage pressure: Laplace's Law revisited. J Wound Care 2014;23:234-46. 